\title{
Sexual Behavior and HIV Testing Practices among Men who have Sex with Men in Portugal
}

\section{Henrique Pereira*}

Department of Psychology and Education, University of Beira Interior, Portugal

\begin{abstract}
The objective of the study was to explore sexual behavior and HIV-testing practices among men who have sex with men (MSM) in Portugal, in light of current international health guidelines that recommend frequent HIV testing for MSM who engage in high-risk behavior. Participants were 304 mostly young, gay or bisexual self-identified MSM. They provided information regarding their HIV status ( $67 \%$ negative, $7 \%$ positive, $26 \%$ didn't know), $24 \%$ had never been tested for HIV, and $15.5 \%$ had been tested only once; main reasons for never having tested previously were: always using condoms, and not feeling at risk. Thus, HIV testing was infrequent and insufficient for early detection of infection, entry into treatment, and protection of sexual partners, since many unprotected sexual practices still occur. Those who tested more were older, self-identified as gay, living in major urban areas and employed. Linear regression predicted that the number of times MSM had penetrative sex without a condom was associated with the number of times they got tested, indicating that they might be using the test itself as a means to gain control of their unprotected sexual practices. Testing campaigns should aim to help MSM become more aware of their risk behavior, decrease fear of testing by explaining available treatment resources and decreasing the stigma associated with HIV, and by publicizing information about free and confidential testing locations.
\end{abstract}

Keywords: HIV testing; Sexual behavior; MSM; Portugal

\section{Introduction}

In Portugal there are an estimated 41,035 HIV-infected individuals [1], and one of the highest prevalence rates in Western Europe [2]. In addition, $81.7 \%$ of the people diagnosed with HIV were men, and although the highest rate of HIV infection is through heterosexual unprotected sex, approximately $15 \%$ of all infections were transmitted via homosexual and/or bisexual unprotected sex [1]. This is particularly important to mention given that this rate has doubled since 2001 among man who have sex with men (MSM) in Portugal, and these estimates only regard the notified cases, not considering the unreported cases. Therefore, MSM remain one of the most at risk groups for HIV transmission [3]. Despite these worrisome statistics, little systematic research has been conducted in Portugal on the contextual factors associated with unsafe sex among MSM, namely HIV testing practices and its relation to demographic variables and sexual behavior.

HIV testing facilitates early detection of infection among at-risk individuals, and early HIV detection is directly associated with improved quality of life and decreased sexual risk behavior [4-6]. Early and successful treatment of HIV-infected individuals with antiretrovirals (ARVs) significantly decreases the chances of HIV transmission to partners.

The US Centers for Disease Control and Prevention [7] recommend testing every three to six months for sexually active MSM. Given that large percentages of HIV-infected persons may be unaware of their infection $[8,9]$, especially among MSM who remain at disproportionate risk of infection [10], frequent testing is important.

Although the percentage of MSM who have never tested for HIV is decreasing [11], many MSM remain untested or test infrequently $[7,12,13]$. Likelihood and frequency of testing may be related to demographic characteristics such as sexual orientation, age and ethnicity $[14,9,15]$; and to fear of positive results, perceived HIV risk, and beliefs about HIV treatment $[16,17]$.

The uncertainty of unknown HIV status is an important motive for testing; however, denial is also a common response to uncertainty. Fear of the consequences of a positive HIV test is widespread and may take several forms. A sense of responsibility towards oneself or one's partner may be a motive for testing. The perception of stigma, from other gay men or from the wider culture, is a barrier to testing [18].
The risk of acquiring HIV infection is related to an interaction of correct knowledge of one's own HIV sero-status and the sero-status of one's sex partner. Most of the research on frequency of HIV testing has occurred in the US, Australia, and China. Nevertheless, very little is known about the frequency of HIV testing among Portuguese MSM and the factors that facilitate or impede testing among this population. The only two studies that tried to describe testing behavior in the context of MSM in Portugal show that some $72 \%$ of men got tested but a lot still needs to be done for improving testing, namely adopting more innovative approaches to HIV testing to improve the efficacy of HIV prevention strategies $[19,20]$.

Therefore, the aim of this study is to contribute to the understanding of the relationship between sexual practices and HIV testing among MSM in Portugal by reporting a sample of 304 demographically diverse men.

\section{Methods}

\section{Participants}

The inclusion criteria for participation in the study were: (1) being MSM, (2) being over 18 years of age, (3) being Portuguese and living in Portugal, and (4) willingness to participate in the study after knowing its objectives. Participants were recruited through snowball sampling, and two methods were used: (1) Informal social networks. The eligible MSM who agreed to participate were asked to refer their friends to participate in the study; and (2) The Internet. The local researcher distributed announcements via local gay websites to reach potential participants, emphasizing that participation was strictly voluntary and confidential.

*Corresponding author: Henrique Pereira, Department of Psychology and Education, University of Beira Interior, Portugal, Tel: 351914572131; E-mail: hpereira@ubi.pt

Received March 19, 2015; Accepted Novmeber 20, 2015; Published November 27,2015

Citation: Pereira H (2015) Sexual Behavior and HIV Testing Practices among Men who have Sex with Men in Portugal. J AIDS Clin Res 6: 524. doi:10.4172/2155 6113.1000524

Copyright: (C) 2015 Pereira $\mathrm{H}$. This is an open-access article distributed under the terms of the Creative Commons Attribution License, which permits unrestricted use, distribution, and reproduction in any medium, provided the original author and source are credited. 
Citation: Pereira H (2015) Sexual Behavior and HIV Testing Practices among Men who have Sex with Men in Portugal. J AIDS Clin Res 6: 524. doi:10.4172/2155-6113.1000524

Page 2 of 5

Demographic data (Table 1) show that the sample is highly differentiated and educated, the majority of men are single and selfidentify as gay. Only $7.2 \%$ of participants state being HIV positive, approximately $26 \%$ report not knowing.

\section{Measures}

\section{Demographic characteristics}

The structured questionnaire covered age, education, marital status, and HIV status. Participants indicated whether they considered themselves (1) gay/homosexual, (2) bisexual, (3) other. The study was not designed to include transgender persons. For the purpose of data analysis, education and marital status were grouped into several categories.

\begin{tabular}{|c|c|c|}
\hline & $\mathrm{n}$ & $\%$ \\
\hline \multicolumn{3}{|l|}{ Self-identification } \\
\hline Gay & 213 & 70.06 \\
\hline Bisexual & 91 & 29.94 \\
\hline \multicolumn{3}{|l|}{ Marital status } \\
\hline Single & 180 & 59.21 \\
\hline Emotional commitment & 58 & 19.08 \\
\hline Divorced & 16 & 5.26 \\
\hline Married to a man & 7 & 2.3 \\
\hline Married to a woman & 12 & 3.95 \\
\hline Civil Union to a man & 23 & 7.57 \\
\hline Civil union to a woman & 8 & 2.63 \\
\hline \multicolumn{3}{|l|}{ Education } \\
\hline Up to 9 years of school & 27 & 8.88 \\
\hline Up to 12 years of school & 73 & 24.01 \\
\hline University/college attendance & 79 & 25.98 \\
\hline Pre-graduate degree & 56 & 18.43 \\
\hline Post-graduate degree & 69 & 22.7 \\
\hline \multicolumn{3}{|l|}{ HIV status } \\
\hline Negative & 203 & 66.77 \\
\hline Positive & 22 & 7.24 \\
\hline Does not know & 79 & 25.99 \\
\hline
\end{tabular}

Mean age $32.30, \mathrm{SD}=11.28$, median $=31$

Table 1: Demographic characteristics $(n=304)$.

\section{Sexual practices}

Participants were asked to recall their sexual experiences and their sexual behaviors over the last two months. Information was collected regarding: (1) receptive anal sex; (2) insertive anal sex; (3) receptive and insertive oral sex.

\section{HIV testing history}

We inquired whether the participants had tested for HIV previously, reasons for never testing, assumptions about status among those not tested, reasons for first testing among those tested, and frequency of testing for those with more than one test.

\section{Analyses}

Analysis was carried out using SPSS version 21. Variables were analyzed using simple frequency and percentage. Logistic regression was carried out on condom use to predict condomless intercourse (dependent variable) with sexual pleasure (independent variable), significant at $\mathrm{p}<0.05$. The $\mathrm{t}$-test and ANOVAs were used to compare differences in groups of MSM using a condom and not using a condom, within the previous two months. All tests were two-tailed.

\section{Ethics statement}

The Institutional Review Boards of the Research Unit of Health and Psychology from the Institute of Applied Psychology in Lisbon, Portugal, approved this study.

\section{Results}

\section{Sexual practices}

Table 2 shows the results for the sexual practices within the last two months, using or not using a condom. Significant differences were found between having sex with or without a condom for receptive anal sex (more men penetrated the participants with a condom, $\mathrm{p}=0.036$ ), for insertive anal sex (more participants penetrated another man with a condom, $\mathrm{p}=0.012$ ), and for oral sex (all differences indicate that a condom is much less used for this type of sex, $\mathrm{p}<0.001$ ).

\section{HIV testing history}

Table 3 shows the HIV testing history of the sample. About $24 \%$ of

\begin{tabular}{|c|c|c|c|c|c|}
\hline Sexual practices within the last two months & $\begin{array}{l}\text { With or Without a } \\
\text { condom }\end{array}$ & Mean & Std. Deviation & $\mathbf{t}$ & $p$ \\
\hline \multirow[t]{2}{*}{ How many times were you penetrated } & With a condom & 2.89 & 6.78 & -.03 & .978 \\
\hline & Without a condom & 2.90 & 8.71 & & \\
\hline \multirow[t]{2}{*}{ How many men penetrated you } & With a condom & 1.36 & 3.70 & 2.10 & $.036^{*}$ \\
\hline & Without a condom & .72 & 3.46 & & \\
\hline \multirow[t]{2}{*}{ How many times did you penetrate } & With a condom & 3.69 & 9.60 & .41 & .680 \\
\hline & Without a condom & 3.36 & 9.13 & & \\
\hline \multirow[t]{2}{*}{ How many men did you penetrate } & With a condom & 2.12 & 7.69 & 2.51 & $.012^{*}$ \\
\hline & Without a condom & 0.84 & 3.57 & & \\
\hline \multirow[t]{2}{*}{ How many times did you perform oral sex } & With a condom & 1.38 & 6.60 & -8.47 & $.000^{* *}$ \\
\hline & Without a condom & 8.73 & 12.95 & & \\
\hline \multirow[t]{2}{*}{ How many men did you perform oral sex to } & With a condom & .65 & 4.02 & -4.86 & $.000^{* *}$ \\
\hline & Without a condom & 3.23 & 7.88 & & \\
\hline \multirow{2}{*}{$\begin{array}{l}\text { How many times did someone perform oral sex } \\
\text { on you }\end{array}$} & With a condom & .85 & 4.54 & -8.73 & $.000^{* *}$ \\
\hline & Without a condom & 9.01 & 14.98 & & \\
\hline \multirow[t]{2}{*}{ How many men performed oral sex on you } & With a condom & .71 & 4.29 & -4.26 & $.000^{* *}$ \\
\hline & Without a condom & 3.41 & 9.73 & & \\
\hline
\end{tabular}

${ }^{*} p<0.05 ;{ }^{* *} p<0.001$

Table 2: Results for "sexual practices within the last two months", using or not using a condom ( $n=304)$. 
Citation: Pereira H (2015) Sexual Behavior and HIV Testing Practices among Men who have Sex with Men in Portugal. J AIDS Clin Res 6: 524. doi:10.4172/2155-6113.1000524

Page 3 of 5

participants had never been tested for HIV, and about $16 \%$ had been tested only once. Also, nearly $24 \%$ of men had tested 6 or more time for HIV. Gay-identified men reported significantly higher proportions $(\mathrm{t}$ $(293)=4.63 ;<0.001)$ when compared to bisexual-identified men.

Table 4 shows the reasons for not testing among those who never tested. The most frequent reasons for not testing were always using condoms and not feeling at risk. No significant differences between gay or bisexual-identified men were found except for other reasons.

Table 5 shows reasons for testing among those previously tested. Almost half of the men claimed their primary reason wanted to know if

\begin{tabular}{|c|c|c|c|c|}
\hline & Total & Gay & Bisexual & $(\mathrm{n}=91)$ \\
\hline & $(\mathrm{N}=304)$ & $(\mathrm{n}=213)$ & $\mathrm{M}(\mathrm{SD})$ \\
\hline $\begin{array}{c}\text { Number of times tested } \\
\text { for HIV }\end{array}$ & $2.85(2.33)$ & $3.26(2.24)$ & $1.95(2.29)$ & \\
\hline 0 & $23.9 \%$ & $10.1 \%$ & $13.8 \%$ & \\
\hline 1 & $15.5 \%$ & $11.4 \%$ & $4.03(293)$ \\
\hline 2 & $9.4 \%$ & $6.7 \%$ & $2.7 \%$ & \\
\hline 3 & $10.1 \%$ & $6.7 \%$ & $3.3 \%$ & \\
\hline 4 & $9.4 \%$ & $8.1 \%$ & $1.3 \%$ & \\
\hline 5 & $7.7 \%$ & $7.1 \%$ & \\
\hline+6 & $23.9 \%$ & $18.5 \%$ & \\
\hline
\end{tabular}

Table 3: HIV testing history and prevalence by sexual orientation

\begin{tabular}{|c|c|c|c|c|c|c|}
\hline & & Total & Gay & Bisexual & & \\
\hline & & $(N=73)$ & $(n=31)$ & $(n=40)$ & Chi-Square (df) & $p$ \\
\hline \multirow[t]{2}{*}{ Hard to get tested } & Yes & $11.3 \%$ & $5.0 \%$ & $6.3 \%$ & \multirow[t]{2}{*}{$0.016(1)$} & \multirow[t]{2}{*}{0.900} \\
\hline & No & $88.8 \%$ & $37.5 \%$ & $51.2 \%$ & & \\
\hline \multirow[t]{2}{*}{ Not knowing where to get tested } & Yes & $27.5 \%$ & $11.3 \%$ & $16.3 \%$ & $0.031(1)$ & 0.859 \\
\hline & No & $72.5 \%$ & $31.3 \%$ & $41.3 \%$ & & \\
\hline \multirow[t]{2}{*}{ Fear of discrimination } & Yes & $12.5 \%$ & $6.3 \%$ & $6.3 \%$ & \multirow[t]{2}{*}{$0.263(1)$} & \multirow[t]{2}{*}{0.608} \\
\hline & No & $87.5 \%$ & $36.3 \%$ & $51.2 \%$ & & \\
\hline \multirow[t]{2}{*}{ Shame to be perceived as homosexual } & Yes & $12.5 \%$ & $7.5 \%$ & $5.0 \%$ & \multirow[t]{2}{*}{$1.432(1)$} & \multirow[t]{2}{*}{0.231} \\
\hline & No & $87.5 \%$ & $35.0 \%$ & $52.5 \%$ & & \\
\hline \multirow[t]{2}{*}{ Fear of finding out results } & Yes & $23.8 \%$ & $12.5 \%$ & $11.3 \%$ & \multirow[t]{2}{*}{$1.047(1)$} & \multirow[t]{2}{*}{0.306} \\
\hline & No & $76.3 \%$ & $30.0 \%$ & $46.3 \%$ & & \\
\hline \multirow[t]{2}{*}{ Don't feel at risk } & Yes & $57.5 \%$ & $21.3 \%$ & $36.3 \%$ & \multirow[t]{2}{*}{$1.361(1)$} & \multirow[t]{2}{*}{0.243} \\
\hline & No & $42.5 \%$ & $21.3 \%$ & $21.3 \%$ & & \\
\hline \multirow[t]{2}{*}{ Always using condoms } & Yes & $75.0 \%$ & $33.8 \%$ & $41.3 \%$ & \multirow[t]{2}{*}{$0.614(1)$} & \multirow[t]{2}{*}{0.433} \\
\hline & No & $25.0 \%$ & $8.8 \%$ & $16.3 \%$ & & \\
\hline \multirow[t]{2}{*}{ Other reasons } & Yes & $13.8 \%$ & $10.0 \%$ & $3.8 \%$ & \multirow[t]{2}{*}{$4.768(1)$} & \multirow[t]{2}{*}{$0.029^{*}$} \\
\hline & No & $86.3 \%$ & $32.5 \%$ & $53.8 \%$ & & \\
\hline
\end{tabular}

${ }^{*} \mathrm{p}<0.05$

Table 4:Reasons for not testing among those never tested.

\begin{tabular}{|c|c|c|c|c|c|c|}
\hline & & Total & Gay & Bisexual & & \\
\hline & & $(N=231)$ & $(n=181)$ & $(n=50)$ & Chi-Square (df) & $p$ \\
\hline \multirow[t]{2}{*}{ Wanting to know if was infected } & Yes & $45.4 \%$ & $34.4 \%$ & $11.0 \%$ & \multirow[t]{2}{*}{$0.090(1)$} & \multirow[t]{2}{*}{0.764} \\
\hline & No & $54.6 \%$ & $42.3 \%$ & $12.3 \%$ & & \\
\hline \multirow[t]{2}{*}{ Had had unprotected sex } & Yes & $23.3 \%$ & $18.5 \%$ & $4.8 \%$ & \multirow[t]{2}{*}{$0.260(1)$} & \multirow[t]{2}{*}{0.610} \\
\hline & No & $76.7 \%$ & $58.1 \%$ & $18.5 \%$ & & \\
\hline \multirow[t]{2}{*}{ Found out that a sex partner was HIV infected } & Yes & $5.7 \%$ & $4.4 \%$ & $1.3 \%$ & \multirow[t]{2}{*}{$0.001(1)$} & \multirow[t]{2}{*}{0.981} \\
\hline & No & $94.3 \%$ & $72.2 \%$ & $22.0 \%$ & & \\
\hline \multirow{2}{*}{$\begin{array}{l}\text { Accompanied friend for testing and got motivated } \\
\text { to get tested }\end{array}$} & Yes & $7.5 \%$ & $5.3 \%$ & $2.2 \%$ & \multirow[t]{2}{*}{$0.378(1)$} & \multirow[t]{2}{*}{0.539} \\
\hline & No & $92.5 \%$ & $71.4 \%$ & $21.1 \%$ & & \\
\hline \multirow[t]{2}{*}{ Started a relationship } & Yes & $23.8 \%$ & $18.1 \%$ & $5.7 \%$ & \multirow[t]{2}{*}{$0.021(1)$} & \multirow[t]{2}{*}{0.885} \\
\hline & No & $76.2 \%$ & $58.6 \%$ & $17.6 \%$ & & \\
\hline \multirow[t]{2}{*}{ It was part of a physical } & Yes & $37.0 \%$ & $27.3 \%$ & $9.7 \%$ & \multirow[t]{2}{*}{$0.602(1)$} & \multirow[t]{2}{*}{0.438} \\
\hline & No & $63.0 \%$ & $49.3 \%$ & $13.7 \%$ & & \\
\hline \multirow[t]{2}{*}{ Other reasons } & Yes & $9.7 \%$ & $6.2 \%$ & $3.5 \%$ & \multirow[t]{2}{*}{$2.306(1)$} & \multirow[t]{2}{*}{0.129} \\
\hline & No & $90.3 \%$ & $70.5 \%$ & $19.8 \%$ & & \\
\hline
\end{tabular}

Table 5: Reasons for testing among those previously tested. 
Citation: Pereira H (2015) Sexual Behavior and HIV Testing Practices among Men who have Sex with Men in Portugal. J AIDS Clin Res 6: 524. doi:10.4172/2155-6113.1000524

Page 4 of 5

\begin{tabular}{|c|c|c|c|}
\hline & $\mathrm{M}(\mathrm{SD})$ & $t(d f) / B e t a / F(d f)$ & $p$ \\
\hline $\begin{array}{l}\text { Age } \\
\text { Younger }(<31) \\
\text { Older }(>32)\end{array}$ & $\begin{array}{l}3.46(4.66) \\
4.76(5.03)\end{array}$ & $t(287)=-2.286$ & $0.023^{*}$ \\
\hline $\begin{array}{l}\text { Sexual Orientation } \\
\text { Gay } \\
\text { Bisexual }\end{array}$ & $\begin{array}{l}4.62(4.88) \\
2.92(4.66)\end{array}$ & $\beta=-0.233$ & $<0.001^{* *}$ \\
\hline $\begin{array}{l}\text { Place of residence } \\
\text { Major Urban area } \\
\text { Smaller Urban area }\end{array}$ & $\begin{array}{l}4.45(4.99) \\
3.28(4.49)\end{array}$ & $\beta=-0.127$ & $0.029^{*}$ \\
\hline $\begin{array}{l}\text { Marital Status } \\
\text { Single } \\
\text { Married or civil union to a man } \\
\text { Married or civil union to a woman } \\
\text { Emotional commitment to a man } \\
\text { Divorced }\end{array}$ & $\begin{array}{l}4.25(5.29) \\
3.86(3.99) \\
2.14(2.49) \\
4.40(4.49) \\
4.47(5.05)\end{array}$ & $\beta=0.043$ & $<0.001^{* *}$ \\
\hline $\begin{array}{l}\text { Education } \\
\text { Up to } 12 \text { years of school } \\
\text { University education }\end{array}$ & $\begin{array}{l}4.06(5.49) \\
4.11(4.53)\end{array}$ & $\beta=0.029$ & 0.638 \\
\hline $\begin{array}{l}\text { Work Status } \\
\text { Unemployed } \\
\text { Self employed } \\
\text { Employed by employer } \\
\text { Student } \\
\text { Other }\end{array}$ & $\begin{array}{l}3.75(4.71) \\
3.78(4.37) \\
4.80(5.07) \\
2.37(4.30) \\
3.13(3.60)\end{array}$ & $F(4 ; 290)=3.008$ & $0.019^{*}$ \\
\hline $\begin{array}{l}\text { Sexual behavior within the last two month } \\
\text { condom } \\
\text { How many times were you penetrated } \\
\text { How many men penetrated you } \\
\text { How many times did you penetrate } \\
\text { How many men did you penetrate }\end{array}$ & $\begin{array}{l}2.90(8.71) \\
0.72(3.46) \\
3.36(9.13) \\
0.84(3.57)\end{array}$ & $\begin{array}{l}\beta=0.011 \\
\beta=-0.101 \\
\beta=0.000 \\
\beta=0.199\end{array}$ & $\begin{array}{l}0.900 \\
0.164 \\
0.997 \\
0.012^{*}\end{array}$ \\
\hline
\end{tabular}

${ }^{*} p<0.05 ;{ }^{* *} p<0.001$

Table 6: demographic variables and sexual behavior without a condom differences based on HIV testing (number of times tested).

they were infected. Thirty seven per cent were tested as part of a physical exam and over $23 \%$ mentioned that they had started a relationship or had had unprotected sex. Only almost $6 \%$ found out that a sex partner was HIV infected. No significant differences between gay or bisexualidentified men were found.

Table 6 presents the associations of demographic variables as well as sexual behavior without a condom variables and HIV testing (number of times tested over a lifetime). HIV testing was associated with age, sexual orientation, place of residence, marital status, work status, and how many times was penetrated without a condom.

\section{Discussion}

In this MSM sample, HIV testing was infrequent and insufficient, particularly in the case of bisexual-identified MSM. Several measures could be taken to counteract this situation. Testing campaigns could be aimed to help MSM, particularly those not gay identified, to become more aware of the behaviors that put them at risk. Given the observed variations in likelihood and frequency of HIV testing according to sexual identity, HIV testing campaigns should highlight that regardless of sexual or gender identity, individuals who engage in sexual risk behavior should be tested regularly. Furthermore, the finding that only $23.3 \%$ ( $18.5 \%$ for gay men, and $4.8 \%$ for bisexual men) reported having been tested because they had unprotected sex is worrisome considering the number of unprotected sexual practices that they engage in, and this is consistent with previous research $[21,22]$. This finding suggests very low risk perception in this population despite apparently high levels of risk behavior, considering that the majority of the participants say that they are not in a relationship.

Fear of testing and finding out about results was addressed by $24 \%$ of participants. This could be decreased by disseminating information on currently available treatments for those found to be infected.
$27.5 \%$ mentioned that they didn't know where to get tested, therefore, publicizing information about free and confidential testing locations in the country could further increase testing, particularly for those concerned about costs.

Although Portugal offers health coverage to all citizens, there is a network of HIV detection services, and free anonymous testing is available in health centers, discrimination and fear of rejection (not only because of the disease itself, but also because of being perceived as gay or bisexual) still exists, which may dissuade some people from seeking HIV testing at such facilities.

Furthermore, including HIV testing in regular physical exams, both in private and public settings, could increase both the number of individuals and the frequency of testing. Developing campaigns to decrease HIV-associated stigma could facilitate test-seeking behaviors. With the legalization of same-sex marriage, Portugal is now seen as an example in decreasing sexual-orientation-based discrimination. Lessons learned through that process should be applied to further erode stigmatization of HIV.

Finally, the association of the number of prior HIV testing with socio-demographic indicators of social marginalization (age, marital status, bisexual identity or work status) indicates an urgent need to promote and facilitate HIV testing among the most disenfranchised sectors. On the other hand, the persistent occurrence of risky sexual practices forces us to accept that much is still left to be done in the field of reducing HIV related behaviors and to promote HIV testing among MSM.

This was a cross-sectional study, and although data were collected at a single point in time, they are useful as a baseline measure against which other assessments at other times and at other venues can be compared. Nevertheless, limitations to this study include the fact that 
self-reported data provide an opportunity for response bias. The men surveyed in this study could have downplayed or overstated their actual behavior. Also, since this was a convenience sample, hence results cannot be generalized.

The results of the few studies conducted with Portuguese MSM [23] indicate that cultural variables may also be important in understanding MSM responses to HIV testing and its influence on the attribution of importance to sexual practices, since cultures transmit values and expectations that influence the sexual behaviors of their members. It is critical that we understand cultural influences on behaviors relevant to HIV risk to reduce the further spreading of HIV among MSM.

According to a report from the Commissioner for Human Rights from the Council of Europe [24], Portuguese people are not comfortable about having a homosexual person as neighbor, and are against samesex marriage and same-sex parenting. Consequently, the identity development of MSM individuals is restricted by these negative societal attitudes, which generally results in the internalization of the stigma associated with their sexual and/or gender identity [25], which has been shown to be associated with risky sexual behaviors [26].

Negotiations between HIV testing and a dislike of condoms seem to be given as justifications for unprotected sex between MSM. Portuguese (MSM) erotic culture, and stigma/discrimination, pressure to omit or concede their status, along with the added security of an undetectable viral load due to current adherence to medication all may lead to the rationalization of how risk is produced and Portuguese MSM may feel more likely to defend unprotected sex as not only being more pleasurable but also as signifying a return to an intimate relationship and to a sense of 'normality' weakened by the public health messages that view sexual risk through a biomedical lens only and deny the significance and meaning given to sex and condoms within a relationship and the unquestionable force of love, pleasure and intimacy [27].

Perceptions of low sexual control have been frequently used as justification for unprotected anal sex in studies with MSM, but failed to operationalize HIV testing patterns as a motivator for such exposure. Discrimination toward homosexual behavior is a context of risk and oppression, which have been found to be strong predictors of HIV risk among MSM men, but the contribution of this study forces us to admit that testing efforts that could counteract further spread of the epidemic needs to be prioritized in the development of condoms and other sexual safety measures as well as in the promotion of their use. Also, new strategies to implement access to the test in Portugal, such as rapid HIV screening, should be discussed.

\section{References}

1. Departamento de Doenças Infecciosas (DDI) (2012) Infeção VIH/SIDA: a situação em Portugal a 31 de dezembro de 2011. Lisboa: INSA

2. UNAIDS (2013) UNAIDS Report on the global AIDS epidemic. WHO Library Cataloguing in Publication Data.

3. Lorimer K, Kidd L, Lawrence M, McPherson K, Cayless S, et al. (2013) Systematic review of reviews of behavioural HIV prevention interventions among men who have sex with men. AIDS Care 25: 133-150.

4. Oberzaucher N, Baggaley R (2002) HIV voluntary counselling and testing: A gateway to prevention and care (UNAIDS/02.41E).

5. Weinhardt LS, Carey MP, Johnson BT, Bickham NL (1999) Effects of HIV counseling and testing on sexual risk behavior: a meta-analytic review of published research, 1985-1997. Am J Public Health 89: 1397-1405.

6. World Health Organization (2004) Rapid HIV tests: Guidelines for use in HIV testing and counselling services in resource-constrained settings.
7. Centers for Disease Control and Prevention (CDC) (2011) HIV testing among men who have sex with men--21 cities, United States, 2008.MMWR Morb Mortal Wkly Rep 60: 694-699.

8. MacKellar DA, Valleroy LA, Anderson JE, Behel S, Secura GM, et al. (2006) Recent HIV testing among young men who have sex with men: correlates, contexts, and HIV seroconversion.Sex Transm Dis 33: 183-192.

9. Sifakis F, Hylton JB, Flynn C, Solomon L, MacKellar DA, et al. (2010) Prevalence of HIV infection and prior HIV testing among young men who have sex with men. The Baltimore young men's survey.AIDS Behav 14: 904-912.

10. Sumartojo E, Lyles C, Choi K, Clark L, Collins C, et al. (2008) Prevalence and correlates of HIV testing in a multi-site sample of young men who have sex with men.AIDS Care 20: 1-14.

11. Helms DJ, Weinstock HS, Mahle KC, Bernstein KT, Furness BW, et al. (2009) HIV testing frequency among men who have sex with men attending sexually transmitted disease clinics: Implications for HIV prevention and surveillance. J Acquir Immune Defic Syndr 50: 320-326.

12. Guy R, Goller JL, Spelman T, El-Hayek C, Gold J, et al. (2010) Does the frequency of HIV and STI testing among men who have sex with men in primary care adhere with Australian guidelines?Sex Transm Infect 86: 371-376.

13. MacKellar DA, Valleroy LA, Anderson JE, Behel S, Secura GM, et al. (2006) Recent HIV testing among young men who have sex with men: correlates, contexts, and HIV seroconversion.Sex Transm Dis 33: 183-192.

14. Nelson KM, Thiede H, Hawes SE, Golden MR, Hutcheson R, et al. (2010) Why the wait? Delayed HIV diagnosis among men who have sex with men.J Urban Health 87: 642-655.

15. Wei C, Ruan S, Zhao J, Yang H, Zhu Y, et al. (2011) Which Chinese men who have sex with men miss out on HIV testing?Sex Transm Infect 87: 225-228.

16. Mikolajczak J, Hospers HJ, Kok G (2006) Reasons for not taking an HIV-test among untested men who have sex with men: an Internet study.AIDS Behav 10: $431-435$

17. Song Y, Li X, Zhang L, Fang X, Lin X, et al. (2011) HIV-testing behavior among young migrant men who have sex with men (MSM) in Beijing, China. AIDS Care 23: 179-186.

18. Lorenc T, Marrero-Guillamón I, Llewellyn A, Aggleton P, Cooper C, et al. (2011) HIV testing among men who have sex with men (MSM): systematic review of qualitative evidence. Health Educ Res 26: 834-846.

19. Carvalho C, Fuertes R, Lucas R, Martins A, Campos MJ, et al. (2013) HIV testing among Portuguese men who have sex with men--results from the European MSM Internet Survey (EMIS).HIV Med 14 Suppl 3: 15-18.

20. Dias S, Gama A, Severo M, Barros H (2011) Factors associated with HIV testing among immigrants in Portugal.Int J Public Health 56: 559-566.

21. Carballo-Diéguez A, Avila MM, Balán IC, Marone R, Pando MA, et al. (2011) Presentación del estudio "Links" de hombres que tienen sexo com hombres en Buenos Aires, Argentina. Actual SIDA 19: 21-25.

22. Carballo-Diéguez A, Balán IC, Dolezal C, Pando MA, Marone R, et al. (2014) HIV testing practices among men who have sex with men in Buenos Aires, Argentina.AIDS Care 26: 33-41.

23. Pereira H (2007) Determinantes do risco e implicações para a saúde nas práticas sexuais de homens que têm sexo com homens. Análise Psicológica 3: 517-527.

24. Commissioner for Human Rights (2011) Discrimination on grounds of sexua orientation and gender identity in Europe. Council of Europe, Strasbourg, France.

25. Costa PA, Pereira H, Leal I (2013) Internalized Homonegativity, Disclosure, and Acceptance of Sexual Orientation in a Sample of Portuguese Gay and Bisexual Men, and Lesbian and Bisexual Women. Journal of Bisexuality 13: 229-244.

26. Dew BJ, Chaney MP (2005) The relationship among sexual compulsivity, internalized homophobia, and HIV at-risk sexual behavior in gay and bisexual users of Internet chat rooms. Sexual Addiction \& Compulsivity: The Journal of Treatment \& Prevention 12: 259-273.

27. Dowsett GW (2003) Some considerations on sexuality and gender in the context of AIDS.Reprod Health Matters 11: 21-29. 